Brain Res Bull. 2010 February 15; 81(2-3): 349-358. doi:10.1016/j.brainresbull.2009.04.004.

\title{
Rodent models of glaucoma
}

\author{
Thomas V. Johnson ${ }^{1,2}$ and Stanislav I. Tomarev ${ }^{1}$ \\ ${ }^{1}$ Molecular Mechanisms of Glaucoma Section, Laboratory of Molecular and Developmental Biology, \\ National Eye Institute, National Institutes of Health, Bethesda, MD, USA \\ ${ }^{2}$ Centre for Brain Repair, Department of Clinical Neuroscience, University of Cambridge, \\ Cambridge, UK
}

\begin{abstract}
Glaucoma is a progressive, age-related optic neuropathy and a leading cause of irreversible blindness in the world. Animal models of glaucoma are essential to our continued efforts of elucidating the natural course of the disease and to developing therapeutic interventions to halt or reverse the progression of the condition. Over the past 10-15 years, rodents have become a popular model organism in which to study glaucoma, because of their high degree of availability, relatively low cost, short life-span, and amenability to experimental and genetic manipulation. In this review, we examine the numerous in vivo and in vitro rodent models of glaucoma, discuss the methods used to generate them, summarize some of the major findings obtained in these models, and identify individual strengths and weaknesses for the various systems.
\end{abstract}

\section{Introduction}

Glaucoma is a neurodegenerative disorder that is characterized by the progressive death of retinal ganglion cells (RGCs) and degeneration of the optic nerve. It is a leading cause of irreversible blindness in the world, ${ }^{1}$ resulting in an initial loss of peripheral vision with central visual defects occurring much later. Like many clinical diseases, it is difficult to study the pathophysiology of glaucoma in human patients. As such, researchers rely on animal models which faithfully replicate important aspects of the condition in order to understand disease mechanisms and to develop new therapies. Of the animal models of glaucoma available, those based on rodent systems are highly attractive for numerous reasons including their potential for experimental (including but not limited to genetic) manipulation, short life span, low cost, and ocular structure and physiology that is relatively comparable to humans.

A wide variety of rodent models for glaucoma exists. As elevated intraocular pressure (IOP) is strongly associated with the onset and progression of glaucoma ${ }^{2-4}$ and the only clinically approved treatments for glaucoma involve pharmacological or surgical therapy to reduce IOP, rodent models of glaucoma that involve optic nerve damage mediated through ocular hypertension are most common. Ocular hypertension occurs naturally in some rodent strains ${ }^{5,} 6$ but can also be induced experimentally in wild-type rats and mice by surgical procedures or by genetic manipulation. Other models used to study death of RGCs have been

Corresponding Author: Stanislav I. Tomarev, Ph.D., Chief, Molecular Mechanisms of Glaucoma Section, Laboratory of Molecular and Developmental Biology, National Eye Institute, National Institutes of Health, 5635 Fishers Lane, Room 1122, Bethesda, MD, 20892, USA, Tel: (301)-496-8524, Fax: (301)-402-0781, tomarevs@nei.nih.gov.

Publisher's Disclaimer: This is a PDF file of an unedited manuscript that has been accepted for publication. As a service to our customers we are providing this early version of the manuscript. The manuscript will undergo copyediting, typesetting, and review of the resulting proof before it is published in its final citable form. Please note that during the production process errors may be discovered which could affect the content, and all legal disclaimers that apply to the journal pertain. 
developed and rely on genetic mutations, mechanical trauma to the optic nerve, toxic insult to retinal neurons, or the induction of retinal ischemia. Although some of these models may not be accepted as "true" glaucoma models, they allow the comparison of processes leading to RGC death induced by different types of initial insults, which may help to differentiate between pathways that are specific to glaucoma versus RGC dysfunctions that are IOP-independent. Finally, experiments that utilize cell culture or tissue culture derived from rodents reproduce the complexity of the natural environment only partially, but they provide a highly controllable system that can reduce the noise of data obtained purely in vivo.

Although no single experimental model is ideal, each of the existing systems have been successfully used to uncover important aspects of glaucoma pathology and might be used to develop novel therapies for the disease in the future. This review will describe the rodent models of glaucoma that have been developed while briefly identifying their individual strengths and weaknesses.

\section{Measuring intraocular pressure in rodents}

It has been demonstrated that the extent and duration of IOP elevation in a wide variety of glaucoma models is positively correlated with RGC loss, optic nerve damage, and functional visual deficit. In order to interpret data obtained in models of ocular hypertension, it is important to be able to accurately and precisely measure IOP in living animals over time. The most direct method available to measure IOP in rodents is by fluid manometry using a pressure transducer following cannulation of the anterior chamber with a microneedle. ${ }^{7}$ While this gold-standard technique is highly accurate, it is an invasive method that has certain limitations. Healing of the cornea at the cannulation site must occur between successive measurements. Moreover, IOP must be measured under general anesthesia, which has been shown to quickly and substantially reduce IOP in some cases. ${ }^{8,}{ }^{9}$ However, effects of anesthetics can be minimized if appropriate care is taken. ${ }^{5}$

To overcome the limitations of invasive techniques, non-invasive methods of tonometry have been applied to rodents. Modifications of the Goldmann tonometer and pneumatonometer have been used to measure IOP in these animals, but these approaches are somewhat cumbersome. A fiber-optic signal conditioner equipped with a pressure transducer was successfully used to measure IOP in anesthetized mice. ${ }^{10-12}$ The TonoPen has been utilized with some success in rodents ${ }^{13}$ but the relatively large tip which was originally designed for human use appears to produce less reliable results in mice. More recently, an impact-induction tonometer, the TonoLab, was developed and has shown greater efficacy in measuring IOP in conscious rodents. In direct comparisons between the TonoPen or TonoLab and microneedle manometry, the TonoLab appears to produce more accurate measurements. ${ }^{14,}{ }^{15}$ However, the accuracy of the TonoLab has been called into question when measuring relatively low IOPs 9,16 and modest IOP changes in rats measured by the TonoPen were reportedly not detected using the TonoLab. ${ }^{16}$ Both TonoPen and TonoLab require a nontrivial amount of investigator training to obtain reliable readings, though our experience has shown the TonoLab to be more user friendly.

\section{Genetic rodent models of glaucoma}

There are numerous rodent lines in which glaucomatous-like pathology occurs due to genetic mutations that lead to the disruption of normal physiology in either aqueous humor dynamics or RGC biology. A main advantage of working with such lines is that animals within a particular line produce more uniform responses in terms of IOP elevation and damage to the retina and optic nerve as compared to surgically induced models. Additionally, a large number of animals may be obtained and no training is needed to produce affected rodents. Perhaps most importantly, however, is that the production of animals bearing specific mutations that have been identified in human glaucoma can be used to investigate the molecular mechanisms by 
which particular gene defects lead to the disease. Moreover, novel mutations in rodents that lead to glaucoma may illuminate yet-unidentified genetic predispositions in human populations.

\section{Ocular hypertensive models}

The DBA/2J mouse strain is a popular model of secondary glaucoma and is one of the best characterized models of glaucoma in general. ${ }^{17} \mathrm{DBA} / 2 \mathrm{~J}$ mice have mutations in two genes, Tyrp1 and Gpnmb, encoding tyrosinase-related and glycosylated transmembrane proteins, respectively. These mutations lead to pigment dispersion, iris transillumination, iris atrophy, and anterior synechia. ${ }^{18}$ The consequential blockade of aqueous outflow results in ocular hypertension by the age of 9 months, which is accompanied by the canonical symptoms of glaucoma - death of the RGCs, optic nerve atrophy and cupping, and visual deficits. ${ }^{17}$ Although no subclass of the RGCs appears especially vulnerable or resistant to degeneration in this model, fan-shaped sectors of cell death and survival radiating from the ONH have been detected. ${ }^{19}$ It has been suggested that axon damage at the optic nerve head might be a primary lesion in this model, which coincides with theories regarding the pathophysiology of human glaucoma. ${ }^{19}$ Another DBA/2 substrain, DBA/2NNia, also develops elevated IOP and demonstrates RGC loss and optic nerve degeneration when aged. However, depletion of cells in the inner and outer nuclear layers and significant damage of the photoreceptor cells in fifteenmonth-old mice have also been observed. ${ }^{20}$ While DBA/2 animals serve as powerful models of glaucoma that do not require specialized induction techniques and that are readily available commercially, the fact that these animals develop glaucoma relatively late in life necessitates a significant time commitment for experimentation. In DBA/2J mice, susceptibility of RGCs to artificial IOP elevation increases with age. ${ }^{21}$ It should be also mentioned that DBA/2J mice are more resistant to the RGC death after the optic nerve crash than 14 other inbred lines of mice tested. It was suggested that 2 dominant loci are linked to the resistance phenotype. ${ }^{22}$

Several important observations with far-reaching implications for the pathogenesis of human glaucoma have been made using the DBA/2J model. For example, the proapoptotic protein BAX was identified as being necessary for RGC death but was not involved in RGC axon degeneration, suggesting that BAX may be a candidate human glaucoma susceptibility gene. ${ }^{23}$ Similar to the results obtained with rat and monkey models, ${ }^{24}, 25$ genes involved in glial activation and immune response are activated in DBA/2J retina as shown by array hybridization. ${ }^{26}$ The complement component $\mathrm{C} 1 \mathrm{q}$ is upregulated in the retina in several animal models of glaucoma as well as human glaucoma with timing that suggests it might play a role in pathogenesis. ${ }^{25}$ Recent data suggests that complement proteins opsonize CNS synapses during a distinct window of postnatal development and that the complement proteins $\mathrm{Clq}$ and $\mathrm{C} 3$ are required for synapse elimination in the developing retinogeniculate pathway. ${ }^{27} \mathrm{In} \mathrm{DBA} /$ $2 \mathrm{~J}$ mice, C1q relocalizes to adult retinal synapses at an early stage of glaucoma prior to obvious neurodegeneration. Taken together, these data indicate that $\mathrm{C} 1 \mathrm{q}$ in the adult glaucomatous retina marks synapses for elimination at early stages of disease suggesting that the complement cascade mediates synapse loss in glaucoma. ${ }^{27}$ Novel therapeutic strategies for glaucoma have also been identified in these mice. For instance, high-dose $\gamma$-irradiation accompanied by syngenic bone marrow transfer protected RGCs in DBA/2J. ${ }^{28}$ A host of other compounds appears to be neuroprotective in this model of glaucoma as well. ${ }^{29-32}$

While the DBA/2J strain represents a model of glaucoma that was discovered retrospectively, transgenic and knockout approaches have been used to prospectively develop other mouse models. Several lines of transgenic mice were developed that express mutated mouse (Tyr423His) or human (Tyr437His) myocilin (MYOC) in the eye drainage structures. ${ }^{11,33}$ The myocilin gene encodes a secreted glycoprotein. Tyr437His mutation in MYOC leads to severe glaucoma cases in humans, ${ }^{34}$ and the mouse Tyr423His mutation corresponds to this 
human mutation. ${ }^{35}$ Expression of mutated mouse or human myocilin in the eye drainage structures of mice led to moderate (about $2 \mathrm{~mm} \mathrm{Hg}$ diurnal and $4 \mathrm{~mm} \mathrm{Hg}$ nocturnal) elevation of IOP in animals that were older than one year. ${ }^{11,33}$ This is much less dramatic than IOP elevation in humans carrying the same mutation in the MYOC gene. Patients with the Tyr437His mutation were diagnosed at 20 years of age on average and had a mean maximum IOP of $44 \mathrm{~mm} \mathrm{Hg}$ versus IOP less than $20 \mathrm{~mm} \mathrm{Hg}$ in control population. ${ }^{36}$ Nonetheless, these mice demonstrate progressive degenerative changes in the peripheral RGC layer and optic nerve with normal organization of the drainage structures. Large RGCs were affected more dramatically than the total population of RGCs, showing a dramatic 55\% reduction in the peripheral retina of 18 -month-old transgenic mice. ${ }^{33}$ It has been suggested that mice expressing mutated mouse or human Myoc in the TM represent a mouse model of primary open angle glaucoma. ${ }^{11,33}$ In a separate study, the expression of mutated Myoc allele (Tyr423His) specifically in the iridocorneal angle did not lead to IOP elevation and did not produce any degenerative changes in the retina. ${ }^{37}$ These differences might be explained by differences in the levels of mutated Myoc expression as well as differences in genetic background.

Another model of primary open angle glaucoma was developed by expressing a mutated version of the collagen type-I $\alpha 1$ subunit, which, unlike the wild-type version, cannot be cleaved by matrix metalloproteinase-1. Transgenic mice expressing this form of collagen develop IOP that is elevated by almost $5 \mathrm{~mm} \mathrm{Hg}$ compared to controls at 36 weeks. These mice demonstrated progressive optic nerve axon loss with normal organization of the drainage structures. ${ }^{38}$

A transgenic model of acute angle-closure glaucoma was developed by expressing the calcitonin receptor-like receptor under the control of a smooth muscle $\alpha$-actin promoter. Overexpression of this receptor in the papillary sphincter muscle results in enhanced adrenomedullin-induced sphincter muscle relaxation that causes abrupt, transient rises in IOP to about $50 \mathrm{~mm} \mathrm{Hg}$ at between 30 and 70 days of age. ${ }^{39}$ Although adrenomedullin and calcitonin gene-related peptide have not been implicated in the pathogenesis of the human condition, it has been suggested that adrenomedullin and its receptor in the iris sphincter may present novel targets for the pharmacological treatment of angle-closure glaucoma. ${ }^{39}$

\section{Ocular normotensive models}

While glaucoma is often associated with elevated IOP, glaucomatous changes in the retina and optic nerve sometimes occur at normal IOP; this is termed normal tension glaucoma (NTG). The pathophysiological relationship between glaucomas occurring at normal and elevated IOPs is presently a matter of debate. Accordingly, mice that represent various models of NTG might be used to investigate the mechanisms of and to develop therapies directed towards IOPindependent mechanisms of RGC death. For example, mice deficient in the glutamate transporters GLAST or EAAC1 experience RGC death and typical glaucomatous degeneration of the optic nerve without elevation of IOP ${ }^{40}$ It has been shown that glutathione levels are decreased in Muller cells of GLAST-deficient mice, while administration of a glutamate receptor antagonist prevents RGC loss. Moreover, RGCs are more sensitive to oxidative stress in EAAC1-deficient mice. ${ }^{40}$ Preliminary reports demonstrate that expression of mutated optineurin (E50K) in the eyes of transgenic mice under the control of actin promoter leads to RGC death and degeneration of axons in the optic nerve without IOP elevation. ${ }^{41}$

\section{Developmental models}

Developmental defects in the anterior chamber can lead to developmental glaucomas, although this is rare, accounting for less than $1 \%$ of all human glaucoma cases. Several genes have been implicated in congenital glaucoma and anterior segment dysgenesis in humans, most of which are transcription factors (see Table 1 for summary). They include FOXC1, FOXC2, PITX2, $L M X 1 b$, and $P A X 6 .{ }^{42-44}$ Knockouts of these genes as a rule are embryonically or neonatally 
lethal. For example, $\mathrm{Foxcl}^{-/-}$mice die at birth, while $\mathrm{FoxCl}^{+/-}$animals are viable but have defects in the eye drainage structures without IOP changes. ${ }^{45}$. Similar eye defects are observed in Foxc2 $2^{+-}$mice. It has been suggested that $\mathrm{FoxCl}^{+/-}$and $\mathrm{Foxc2}^{+/-}$mice are useful models for studying anterior segment development and anomalies, and they may lead to the identification of genes that interact with Foxcl and Foxc 2 to produce a phenotype with elevated IOP and glaucoma. ${ }^{45}$ Conditional knockouts of transcription factors implicated in congenital glaucoma may provide a useful tool to study their function in the development of the eye angle structure and glaucoma. One gene implicated in congenital glaucoma, CYP1B1 (Cytochrome P450, family 1, subfamily b, polypeptide 1), encodes an enzyme. Although Cyplbl knockout mice do not develop elevated IOP, they have ocular abnormalities similar to defects in humans with primary congenital glaucoma: small or absent Schlemm's canal, defects in the trabecular meshwork (TM) and attachment of the iris to the trabecular meshwork and peripheral cornea. 46

Expression of $O D A G$ (ocular development-associated gene) under the control of the mouse Crx promoter induced significant elevation of IOP (approximately $50 \%$ above controls) which was not attributed to angle closure. ${ }^{47}$ The $O D A G$ gene product encodes a putative zinc finger protein with a length of 266 amino acids that binds Rab6-GAP and Rab6 proteins. Elevated expression of ODAG led to optic nerve atrophy, and the optic disc of these animals was poorly formed. Unlike human congenital glaucoma, all the cell layers of the transgenic retina were poorly developed, irregularly arranged, and contained fewer cells than those of the wild-type retina. ${ }^{47}$ However, these results support a previous observation that small GTPases (Rab8) might be involved in the pathogenesis of human glaucoma. ${ }^{48}$

\section{Future Genetic Models}

It is expected that new genetic mouse models of glaucoma will be developed in the near future. For example, overexpression of antagonists of Wnt signaling such as sFRP1 in the tissues of the iridocorneal angle may lead to elevation of IOP and a glaucoma-like phenotype. ${ }^{49}$ Such animals were produced in our laboratory and are the subject of ongoing investigations. Separately, mating transgenic animals expressing mutated Myoc with transgenic or knockout lines expressing modified versions of other proteins implicated in glaucoma (optineurin, Cyp1b1) may lead to more pronounced pathology as compared with mutated Myoc alone. Application of different forms of stress to the TM of mutated Myoc transgenic mice through genetic manipulations or diet may also induce stronger pathology. Finally, the random mutagenesis of the mouse or rat genomes may lead to the identification of new genes implicated in glaucoma and new rodent models of this blinding disease.

\section{Glaucoma models involving the induction of ocular hypertension}

The course of glaucomatous pathology in genetic rodent models often is quite long (on the order of several months) and generally not amendable to experimental manipulation. However, there are a number of experimental techniques that can be used to chronically raise the intraocular pressure of rodents on a shorter-term basis and with greater control over the extent of pathology. These include laser photocoagulation of the TM, injection of hypertonic saline into the episcleral veins, cauterization of the episcleral veins, and injection of substances into the anterior chamber to obstruct aqueous outflow. These methods differ according to the maximal level and kinetics of the pressure rise as well as the amount of control that the investigator has over these parameters. Additionally, some methods require specialized equipment and have steeper learning curves than others. As such, investigators should carefully consider which models best suit a particular experimental scenario. 


\section{Laser-induced ocular hypertension}

Aqueous humor drains from the anterior chamber via two routes: through the TM, where Schlemm's Canal empties into episcleral and limbal blood vessels, and the uveoscleral pathway. In most cases, ocular hypertension in humans is associated with impairment in aqueous humor outflow. One common approach to inducing elevated IOP in animal models is by experimentally reducing aqueous humor outflow by laser photocoagulating the tissue involved in drainage. Laser photocoagulation of the trabecular meshwork was shown to increase IOP in rhesus monkeys in the mid 1970 's,${ }^{50}$ but this approach has more recently been applied to rodent models, with obvious benefits as previously described.

Early attempts to induce ocular hypertension in the rat and mouse involved laser photocoagulation of the episcleral and limbal blood vessels. ${ }^{51-53}$ In the first published attempt at laser cauterizing the TM of rats, Ueda et al. ${ }^{54}$ utilized injection of India Ink into the anterior chamber of Wistar rats one week prior to argon laser treatment directed at the TM. The carbon particles, which by the time of laser treatment had accumulated within the anterior chamber angle, absorbed laser energy and produced focal heat thereby generating a localized scarring effect. The authors reported that at least 3 laser treatment spaced 7 days apart were required to produce an IOP of at least $25 \mathrm{~mm} \mathrm{Hg}$ and that discontinuation of laser treatments led to a gradual reduction in IOP. Weekly laser treatments were capable of maintaining IOP at $\geq 20$ $\mathrm{mm} \mathrm{Hg}$ over the course of 12 weeks and resulted in cupping of the optic nerve head, thinning of the nerve fibre layer, and degeneration of the optic nerve. In an attempt to optimize the parameters of the laser application, Levkovitch-Verbin et al. ${ }^{55}$ translimbally applied a higher intensity, longer application of argon laser to various drainage sites in the absence of applied pigment granules. Here, it was reported that photocoagulation of the TM produced elevated IOPs that reached an average maximum of $34 \mathrm{~mm} \mathrm{Hg}$ while concurrent treatment to the limbal vessels augmented the effect to over $40 \mathrm{~mm} \mathrm{Hg}$. IOPs after a single treatment remained elevated for about 3 weeks and significant, progressive RGC loss and optic nerve degeneration was observed.

Laser-induced ocular hypertension has also been applied to mice. Grozdanic et al. ${ }^{56}$ used a diode laser to photocoagulate the TM and episcleral veins of C57/BL6 mice following intracameral injection of indocyanine green, producing IOP elevation to the mid $30 \mathrm{~mm} \mathrm{Hg}$ 's that persisted for at least 30 days. Argon laser treatment of the TM and episcleral vessels in C57/BL6 mice without intracameral injection of indocyanine green also produced significant ocular hypertension which lasted for approximately 4 weeks and produced corresponding RGC loss and optic nerve changes. ${ }^{53,57}$ Flattening of the anterior chamber to facilitate argon laser treatment of the TM has produced elevated IOP for 6 weeks after a single treatment. ${ }^{58}$

While various approaches have been investigated to induce ocular hypertension in rodents via laser treatment to the TM and/or episcleral vessels, results have been generally consistent and demonstrate high utility for this model. Laser photocoagulation of the aqueous outflow pathways produces a moderate level of ocular hypertension that is correlated with RGC loss and optic nerve degeneration. While the length of the IOP elevation is relatively transient (26 weeks), it has been shown that the loss of RGCs and their axons is progressive even after IOP has normalized. ${ }^{55}$ This mirrors the situation sometimes seen in human patients that experience persistent (if slower) visual decline even after the pharmacological or surgical reduction of IOP. The modulation of laser intensity, duration, and spot number provides some ability to control the duration and extent of IOP elevation. Additionally, the pathophysiology of neurodegeneration appears to be relatively specific to RGCs.

There are several limitations to the use of laser-induced ocular hypertension in rodents. First, most of the models discussed utilize an argon laser mounted on a slit lamp and therefore require significant investment in specialized equipment. Second, the differential presence of pigment 
in the chamber angle dramatically alters the uptake of laser energy and the extent of damage produced to the TM. Some investigators have used this to their advantage by administering pigment particles to augment energy uptake. However, this also implies that the parameters of laser administration must be titrated for each strain of animal investigated. Our own experience has demonstrated that laser uptake in pigmented rats is extremely high and variable, and inflammation is exacerbated, resulting in a large variation in subsequent IOP elevation. Therefore this model may be particularly suited for certain strains of rodents. Third, while it is possible to lengthen the time of ocular hypertension by repeating laser treatments, each application results in some level of corneal degeneration so the number of possible repeat treatments is limited. Our own experience has shown that some animals exhibit significant corneal edema leading in some instances to ulceration after two laser treatments. Treatment with a combined topical antibiotic and steroid can be utilized to limit this complication.

\section{Episcleral vein injection of hypertonic saline}

Intraocular pressure can be elevated in rats after sclerosing the TM by injecting a hypertonic saline solution into the episcleral veins using specialized microneedles pulled from borosilicate glass micropipettes. ${ }^{59}$ This technique results in a moderate elevation of IOP within 7-10 days, with a considerable level of variability - between $0-30 \mathrm{~mm} \mathrm{Hg}$ compared to fellow control eyes. In some cases, repeat injections are required if IOP fails to elevate after an initial treatment. ${ }^{60}$ However, ocular hypertension tends to persist for longer periods of time when compared to laser-induced ocular hypertension, with documented IOP elevation sometimes lasting longer than 200 days. ${ }^{59}$ Notably, this model has been combined with cyclodialysis to normalize IOP to baseline levels in rat eyes with ocular hypertension. ${ }^{61}$ Like other forms of ocular hypertension in rodents, this model has been shown to produce progressive RGC loss and optic nerve degeneration. Further, RGC-specific changes to the electroretinogram ${ }^{60}$ and changes in the gene expression pattern in the retina and optic nerve head have been observed in rats using this model. ${ }^{24,62}$

Compared to other rodent models of glaucoma, injection of hypertonic saline requires less specialized equipment. Glass microneedles can be fabricated in the laboratory at relatively low cost. However, the surgical technique of inserting a microneedle into the rat episcleral vein is difficult and requires significant training. To our knowledge, this technique has so far only been applied to rats, likely owing to the much smaller size of the mouse ocular vascular and technical difficulty in tapping those vessels for injection.

\section{Episcleral vein cauterization (EVC)}

IOP may be chronically elevated in rats is by cauterizing two or more episcleral veins, thereby impairing the drainage of aqueous humor from the collecting ducts of Schlemm's canal. ${ }^{63} \mathrm{In}$ this model, the number of episcleral veins cauterized correlates with the extent of pressure elevation. While cauterizing one vein results in no observable IOP increase, two or three veins elevated IOP into the $20 \mathrm{~mm} \mathrm{Hg}$ 's while control eyes remained between $10-15 \mathrm{~mm} \mathrm{Hg}$. Cauterizing four veins produced IOPs near $60 \mathrm{~mm} \mathrm{Hg}$. In the case of three veins being cauterized, IOP spiked to over $50 \mathrm{~mm} \mathrm{Hg}$ before normalizing to between $20-30 \mathrm{~mm} \mathrm{Hg}$, where it remained elevated through a period of at least 2 months. This IOP elevation produces expected loss of RGCs at a rate of approximately $4 \%$ per week, ${ }^{64}$ and it was demonstrated in this model that RGC death induced by ocular hypertension takes place, at least in part, through apoptosis. ${ }^{65} \mathrm{EVC}$ also has been applied to mice. Despite the technical difficulty of the surgery, Ruiz-Ederra and Verkman ${ }^{66}$ were able to achieve an IOP increase of around $100 \%$ that persisted for 4 weeks.

It has been suggested by Morrison et al. ${ }^{16,67}$ that the pathophysiology of the EVC model differs from the other two previously discussed ocular hypertension models. As the IOP becomes 
elevated almost immediately following the cauterization procedure, it has been hypothesized that at least a portion of the ocular hypertension is due to ocular venous congestion. ${ }^{68}$ This is unlikely to be the sole mechanism of ocular hypertension, however, as obstructed aqueous humor outflow was observed in the mouse EVC model. ${ }^{66}$ Additionally, the pattern of induced RGC death might be different in this model. While early axonal degeneration in the previous two models occurs preferentially in the superior region of the optic nerve, EVC appears to produce general RGC loss throughout the periphery of the retina. ${ }^{16}$ Morrison also observed retrospectively that the extent of RGC loss normalized for cumulative IOP exposure in the EVC model is lower that that seen in the other two models, ${ }^{67}$ and hypothesized differential stress forces within the eye as one possible underlying reason.

\section{Injection of substances that induce ocular hypertension}

While the previously discussed methods have relied on experimental ablation of aqueous humor outflow pathways, other techniques aim to block these pathways without inducing overt degradation. Following injection of a variety of substances into the anterior chamber, localization within the anterior chamber angle and subsequent IOP elevation has been observed. Weekly intracameral injections of the extracellular matrix molecule hyaluronic acid in rats, for instance, produced a sustainable ocular hypertension that was followed for up to 10 weeks. ${ }^{69}$ Injection of $10 \mu \mathrm{m}$ latex microspheres with or without the addition of hydroxypropylmethylcellulose (HPM) also blocked drainage through the trabecular meshwork and increased intraocular pressure. ${ }^{70}$ In this case, nine and six weekly repeated injections, respectively, were necessary before a sustained increase in IOP was achieved, which lasted for at least 30 weeks in each case. While it is technically simple and relatively inexpensive to utilize these models, the weekly repeated injections necessary to obtain significant and persistent ocular hypertension makes them very labor intensive. Additionally, it is possible that deleterious side effects such as corneal abnormalities and/or inflammation may become evident over time.

Systemic administration of S-antigen in complete Freund's adjuvant has been utilized to model uveitic glaucoma in rodents. ${ }^{71}$ Following an initial drop in IOP from 2-5 days after S-antigen delivery, IOP increases to an average of $35 \mathrm{mmHg}$ during the following 2 weeks. ${ }^{71}$ The elevated IOP was attributed to angle closure along with an increase in aqueous humor production and possibly concurrent reduction in outflow facility. ${ }^{71}$ Importantly, marked inflammation in both the anterior and posterior chambers is a prominent component of the pathogenesis of this model and interpretation of results obtained using S-antigen delivery must take this fact into account.

\section{Models of experimentally-induced RGC loss not related to ocular hypertension}

In some cases, it may be desirable to induce a relatively specific insult to RGCs in the absence of increased IOP. Common methods of accomplishing this are through mechanical injury of the optic nerve, intraocular injection of toxic agents, or by the induction of ischemia followed by reperfusion. While the mechanism of pathophysiology in these systems does not directly follow that of human glaucoma, insights into RGC neurodegeneration have been gained through using these models. In general, the procedures are quick and relatively easy to perform making them attractive models.

\section{Optic nerve crush or transaction}

Induction of a mechanical injury to the axon of a neuron triggers a degenerative response that flows retrogradely to the soma and is termed Wallerian degeneration. Crush or complete or partial transection of the optic nerve has been utilized to trigger a relatively specific loss of RGCs. The procedure is relatively simple to perform in both rats and mice. Following the 
induction of heavy anesthesia and topical anesthetic, a temporal canthotomy is performed and blunt dissection is used to expose the optic nerve. Care must be taken not to interrupt the orbital blood supply, which tends to be more difficult to accomplish in mice than in rats. Once exposed, the optic nerve may be crushed with calibrated cross-action forceps that are designed to deliver a consistent amount of force. The extent of injury may be altered by modifying the force or length of time of the crush. Alternatively, the optic nerve may be transected with a diamond knife, though care must be taken to preserve the integrity of the retinal arterial blood supply. Following the procedure, it is advisable to examine the retina to confirm that adequate blood flow is present.

RGC degeneration begins quickly following mechanical optic nerve damage. After a severe crush injury in the mouse, RGC survival has been shown to drop to $47 \%$ and $27 \%$ at one and two weeks post-injury, respectively. ${ }^{72}$ However, the published literature includes a wide range of RGC survival rates, some indicating that $90 \%$ of RGCs survive to 2 weeks post-injury and $80 \%$ survive at 4 weeks. ${ }^{73}$ This wide range of results likely indicates substantial differences in the extent of crush administered and attests to the necessity of controlling the severity (force and duration) of the crush. Complete axotomy results in the near-total loss of RGCs within a few weeks. ${ }^{73,} 74$

Importantly, multiple studies have demonstrated that the death of RGCs after optic nerve injury is progressive and that the pathophysiology includes a component of primary damage followed by a wave of secondary degeneration. Thus, when injuring the optic nerve, some axons are not initially damaged by the procedure itself but are susceptible to deleterious downstream factors in the resultant neurotoxic environment. This phenomenon has been utilized for the study of neuroprotection, in order to find methods of preventing the death of RGCs which escaped damage from the primary insult. ${ }^{75,76}$ Partial optic nerve transection has been used as a way to investigate secondary degeneration spatially as opposed to temporally. By creating an axotomy only affecting the superior one-third of the optic nerve, Blair et al. ${ }^{74}$ were able to observe the progressive degeneration of RGCs which were not axotomized. Optic nerve injury has also been utilized to directly compare the course of neurodegeneration that occurs in RGCs as a result of direct damage to the axon versus the to that observed in chronic ocular hypertension. ${ }^{77}$

The benefits of this model lie in the relatively quick onset of pathology and the ease of performing the procedure. Importantly, while ocular hypertension does not play a role in the mechanism underlying RGC loss in this model, it does involve some characteristics that are similar to human glaucoma. It is thought that a significant portion of the primary injury to RGCs in glaucoma is axonal, occurring through mechanical forces stressing the axons at the level of the optic nerve head in the presence of elevated intraocular pressure. ${ }^{78,79}$ Additionally, impairment in retrograde transport of growth factors from the brain to RGC somas via their axons has been implicated in human glaucoma and likely also occurs following mechanical optic nerve injury as well. ${ }^{78,79}$ Therefore, the optic nerve injury model is of particular benefit when investigating how axonal injury plays a role in glaucomatous pathology.

\section{Intraocular injection of excitotoxic agents}

Excitoxicity can be induced in the rodent retina by intravitreal administration of substances which over-activate ionotropic glutamate receptors leading to a rise in intracellular calcium levels and eventual cellular dysfunction and death. There are three major classes of these ligand-gated ion channels: N-methyl-d-aspartate (NMDA) receptors, $\alpha$-amino-3-hydroxy-5methyl-4-isoxazoleproprionic acid (AMPA) receptors, and kainate receptors. In the retina, horizontal cells, bipolar cells, amacrine cells, and ganglion cells have been shown to possess various combinations and subtypes of these receptors and intravitreal administration of glutamate, NMDA, and kainic acid has been used to achieve targeted neurodegeneration of 
these cells. Studies using these compounds have demonstrated that cell death is confined to the inner layers of the retina including, but not limited to, RGCs. Importantly, cells inner nuclear layer also are affected. ${ }^{80} \mathrm{Cells}$ in the outer nuclear layer do not undergo significant degeneration following excitotoxic challenge, possibly owing to the fact that the photoreceptors do not express appreciable levels of the corresponding receptors. ${ }^{81}$

Various forms of administration of excitotoxic compounds are capable of triggering RGC death. Acute high-dose intravitreal administration (20-200 nmol) of glutamate, NMDA, or kainic acid is the most common method of triggering RGC death. In acute models, neurodegeneration is rapid with signs of apoptosis observable just $1 \mathrm{~h}$ after injection. ${ }^{82} \mathrm{Chronic}$ low-dose administration of glutamate ( $2.5 \mathrm{nmol}$ intravitreally every 5 days) triggered the death of $42 \%$ of RGCs over a 3 month period. ${ }^{83}$ Additionally systemic administration of glutamate induces excitotoxicity in neonatal rodents, but is unable to cross the blood-brain barrier of adult animals. The relatively low technical difficulty and cost involved in this technique make it an attractive experimental model.

The importance of this model is underscored by the fact that excitotoxicity has been, rather controversially, implicated as a contributing factor in human glaucoma. As we have seen, experimental administration of glutamate receptor agonists results in RGC death in animal models. Some studies have reported that vitreal levels of glutamate are elevated in human glaucoma patients and monkeys with experimental glaucoma ${ }^{84}$ but subsequent investigations have failed to replicate these results in humans,${ }^{85}$ monkeys with laser induced ocular hypertension, ${ }^{86}$ or rats with laser induced ocular hypertension or optic nerve transection. ${ }^{87}$ Nevertheless, MK-801, an NMDA receptor antagonist, has been shown to possess neuroprotective properties in rat ocular hypertension ${ }^{88}$ and optic nerve crush ${ }^{89}$ models as well as the DBA/2J mouse..$^{90}$ While the precise role of excitotoxicity in human glaucoma is still a matter of considerable debate, this model will continue to serve as a basis for investigating neuroprotective strategies aimed at excitotoxic insults to the CNS.

\section{Ischemia/reperfusion}

The induction of acute retina ischemia for a period of between 30-120 minutes followed by reperfusion causes death within a variety of cell types within the retina. ${ }^{91-94}$ While this model triggers apoptosis in RGCs, damage occurs throughout the various layers of the retina. As such, it can be argued that this model represents global retinal degeneration rather than glaucoma per se. Nonetheless, it has been utilized to investigate RGC death and dysfunction and has been particularly important in investigating the potential role for vascular insufficiency in glaucoma. Ischemia can be induced in the retina through a variety of methods. Cannulation of the anterior chamber of mice and rats with a microneedle allows one to precisely control the intraocular pressure. By setting IOP above the ocular perfusion pressure (generally to about $110 \mathrm{~mm} \mathrm{Hg}$ ), blood flow through the retinal and uveal vasculature is suppressed. IOP can be normalized by reducing the pressure of the perfusion system after the ischemic exposure period is over. While this method involves extreme acute ocular hypertension, the neurodegenerative effect is thought to be mediated primarily through the ischemic insult, though it is possible that other IOP-induced damage to RGCs, similar to that seen in acute glaucoma, may also play a role.

As the central retinal artery feeds the retinal vasculature, transient ligation of the entire optic nerve with a suture is capable of removing the retinal blood supply causing ischemia. ${ }^{95}$ In this case, removal of the suture results in reperfusion after the experimental period. Importantly, however, ligation of the optic nerve likely results in damage to the RGC axons and therefore this method may represent a combination of the ischemia/reperfusion model and the optic nerve crush/damage model. While technically more difficult, it is possible to isolate the central retinal artery from the rest of the optic nerve to ligate the vessel independently, producing a purer insult. 
A relatively less invasive method for producing retinal ischemia has also been reported and involves intravitreal injection of Rose Bengal followed by focal laser stimulation of the dye, which activates platelets leading to local thrombosis of retinal arteries. ${ }^{96}$ The thrombosis can be removed by systemic thrombolytic treatment. While this approach avoids the potential confounding effects of acute ocular hypertension or mechanical damage to the optic nerve, it may induce some level of phototoxicity in the retina.

Retinal ischemia followed by reperfusion is a rather specialized insult that, while triggering the death of RGCs, is not very specific. While there has been some speculation that reduced blood supply to the retina might play a role in glaucoma, it may be only peripheral and therefore the applicability of this model to glaucoma in general is questionable. Nonetheless, this model has been important for investigating the susceptibility of RGCs to vascular insults and mechanisms of RGC death and neuroprotection in general. As it is a relatively easy method with which to work and is one that generates reproducible data, it has proven to be a useful system.

Sustained reductions in retinal blood flow have also been used to model glaucoma in rodents. Retrobulbar delivery of endothelin-1 using an osmotic minipump in the rat causes decreased optic nerve blood flow with resultant RGC loss and optic nerve degeneration without obvious changes to other retinal cell types. ${ }^{97}, 98$ IOP alterations have not been reported in this model, though endothelin- 1 administration in rabbits has been shown to modestly increase IOP by about $5 \mathrm{mmHg}$ for $1-2 \mathrm{~h}$ before significantly reducing IOP for up to 4 days. ${ }^{99}$ Similar to the ischemia/reperfusion model, interpretation of results obtained using this model must be made in light of the fact that the insult is ischemic in nature.

\section{In vitro systems}

While in vivo experimentation is necessary to prove that a phenomenon occurs in complex living organisms, it necessarily involves a milieu of undefined and often uncontrollable factors. As such, in vitro systems are often useful to conduct highly controlled preliminary investigations or to prove a principle in a very specific context. There are at least two types of in vitro systems that are applicable to glaucoma research: RGC culture as carried out on primary cells isolated from rodents or the RGC-5 cell line and retinal explant organ culture.

\section{Retinal ganglion cell culture}

While the culture of RGCs is a minimal system consisting of only the particular cell type that is targeted for death in glaucoma, it can sometimes be extremely useful for assessing the response of this cell type to specific conditions in isolation from the rest of the eye. RGCs may be obtained as a primary culture from freshly isolated rodent retina. Typically, retina is treated chemically or enzymatically to create a dissociated single cell suspension which is then plated in culture. ${ }^{100}$ Over time, RGCs can be distinguished from other cell types present in the culture by morphology as RGCs will extend neuritic processes. Additionally, immunocytochemical staining for RGC-specific antigens such as Thy 1 can be employed. To obtain a purified population of RGCs in culture, immunopanning may be utilized. This technique typically employs a subtraction step in which anti-IgG antibodies are used to remove macrophages and microglia followed by a purification step in which anti-Thy 1 antibodies specifically bind RGCs, which can be subsequently released and cultured. ${ }^{100-102}$

An immortalized cell line derived from the rat, termed the RGC-5 cell line, was developed which is similar to RGCs in that the cells express Thy 1, Brn3C, Trk-A, and a variety of neurotrophic factors. ${ }^{103,} 104$ However, there are many important differences between this cell line and true RGCs which must be taken into account when interpreting results involving these cells. Morphologically, the cells appear glial but do not express glial fibrillary acid protein. 
Electrophysiological investigations suggest that RGC-5 cells do not express the repertoire of electrophysiological ion channels that are characteristic of RGCs. ${ }^{105}$ Additionally, while RGCs are sensitive to apoptosis triggered by the broad-spectrum protein kinase inhibitor staurosporine, this compound actually induces differentiation of RGC-5 cells into a phenotype more characteristic of mature RGCs. ${ }^{105}$ Therefore, while this is a convenient system that has been used to assess many aspects of RGC biology, pharmacology, and electrophysiology, results produced with this cell line must be interpreted with caution.

\section{Retinal explant culture}

Organotypic retinal explant tissue culture has a long history of being useful for investigations involving development and electrophysiology. ${ }^{106,107}$ Historically, the greatest success in maintaining mammalian retinal tissue in culture has been attained with embryonic or fetal animals. Recently, however, strategies have been generated for the relatively long term (greater than two weeks) culture of the adult mammalian retina. ${ }^{108}$ As the procedure for explantation of the retina requires the severing of all axons within the optic nerve followed by the consequential degeneration of RGCs, retinal explant cultures serve as a model of glaucoma. This system is especially useful for experiments which require the complex structural context of multiple retinal cell types but cannot be performed in vivo because of limitations involving tissue access, control over the microenvironment, or confounding systemic factors. The development of defined, serum-free media formulations has further enhanced control over this experimental system.

In this model, retinal tissue with or without the retinal pigment epithelium is obtained from post-mortem rodent eyes following enucleation, and removal of the anterior segment and lens. Retinal tissue is generally cultured on organotypic tissue culture filter inserts, which are laid over a pool of media. Success has been obtained in culturing the whole mounted retina with either the RGC or photoreceptor side facing the filter. The applications for this sort of system include studying RGC electrophysiology, gene therapy, and stem cell therapy. The benefits of this system include its high efficiency and ease to set up, as well as its versatility and high level of control that the investigator has over the model while still maintaining a complex system of multiple cell types. Nonetheless, this in vitro system is extremely simplified when compared to a living eye and experiments obtained in either cell or organ culture must be followed up in vivo.

\section{Conclusions}

Glaucoma is a complex disease with a complicated pathophysiology that is far from being completely understood. Animal models of glaucoma are essential to our continued efforts of elucidating the natural course of the disease and developing therapeutic interventions to halt or reverse the progression of the condition. Rodent models are particularly advantageous because of their high degree of availability, relatively low cost, short life-span, and amenability to experimental and genetic manipulation. However, it is obvious that rodent models of glaucoma are not exact recapitulations of the human condition. Moreover, rodent models of glaucoma have individual strengths and weaknesses that make them particularly suited to answer specific research questions (see Table 1). Therefore results obtained in these systems must be extrapolated only to the extent that a particular model and research question warrants. Nonetheless, continued development of these models and more in-depth exploration of their pathology are likely to contribute to great strides in understanding and treating glaucoma in human patients in the future. 


\section{Acknowledgments}

This research was supported by the Intramural Research Program of the National Eye Institute, National Institutes of Health; a National Institutes of Health Graduate Partnerships Program Fellowship (TVJ); and a Gates-Cambridge Scholarship (TVJ).

\section{References}

1. Quigley HA, Broman AT. The number of people with glaucoma worldwide in 2010 and 2020 . Br J Ophthalmol 2006;90:262-267. [PubMed: 16488940]

2. Kass MA, Heuer DK, Higginbotham EJ, et al. The Ocular Hypertension Treatment Study: a randomized trial determines that topical ocular hypotensive medication delays or prevents the onset of primary open-angle glaucoma. Arch Ophthalmol 2002;120:701-713. discussion 829-730. [PubMed: 12049574]

3. Gordon MO, Beiser JA, Brandt JD, et al. The Ocular Hypertension Treatment Study: baseline factors that predict the onset of primary open-angle glaucoma. Arch Ophthalmol 2002;120:714-720. discussion 829-730. [PubMed: 12049575]

4. Le A, Mukesh BN, McCarty CA, Taylor HR. Risk factors associated with the incidence of open-angle glaucoma: the visual impairment project. Invest Ophthalmol Vis Sci 2003;44:3783-3789. [PubMed: 12939292]

5. Savinova OV, Sugiyama F, Martin JE, et al. Intraocular pressure in genetically distinct mice: an update and strain survey. BMC Genet 2001;2:12. [PubMed: 11532192]

6. Thanos S, Naskar R. Correlation between retinal ganglion cell death and chronically developing inherited glaucoma in a new rat mutant. Experimental eye research 2004;79:119-129. [PubMed: 15183107]

7. John SW, Hagaman JR, MacTaggart TE, Peng L, Smithes O. Intraocular pressure in inbred mouse strains. Investigative ophthalmology \& visual science 1997;38:249-253. [PubMed: 9008647]

8. Jia L, Cepurna WO, Johnson EC, Morrison JC. Effect of general anesthetics on IOP in rats with experimental aqueous outflow obstruction. Invest Ophthalmol Vis Sci 2000;41:3415-3419. [PubMed: 11006233]

9. Johnson TV, Fan S, Toris CB. Rebound tonometry in conscious, conditioned mice avoids the acute and profound effects of anesthesia on intraocular pressure. J Ocul Pharmacol Ther 2008;24:175-185. [PubMed: 18355131]

10. Filippopoulos T, Matsubara A, Danias J, et al. Predictability and limitations of non-invasive murine tonometry: comparison of two devices. Exp Eye Res 2006;83:194-201. [PubMed: 16564045]

11. Senatorov V, Malyukova I, Fariss R, et al. Expression of mutated mouse myocilin induces open-angle glaucoma in transgenic mice. J Neurosci 2006;26:11903-11914. [PubMed: 17108164]

12. Ahmed E, Ma J, Rigas I, et al. Non-invasive tonometry in the mouse. Invest Ophthalmol Vis Sci 2003;44:3336.

13. Moore CG, Milne ST, Morrison JC. Noninvasive measurement of rat intraocular pressure with the Tono-Pen. Investigative ophthalmology \& visual science 1993;34:363-369. [PubMed: 8440590]

14. Saeki T, Aihara M, Ohashi M, Araie M. The efficacy of TonoLab in detecting physiological and pharmacological changes of mouse intraocular pressure--comparison with TonoPen and microneedle manometery. Curr Eye Res 2008;33:247-252. [PubMed: 18350435]

15. Pease ME, Hammond JC, Quigley HA. Manometric calibration and comparison of TonoLab and TonoPen tonometers in rats with experimental glaucoma and in normal mice. J Glaucoma 2006;15:512-519. [PubMed: 17106364]

16. Morrison JC, Johnson E, Cepurna WO. Rat models for glaucoma research. Progress in brain research 2008;173:285-301. [PubMed: 18929117]

17. Libby RT, Anderson MG, Pang IH, et al. Inherited glaucoma in DBA/2J mice: pertinent disease features for studying the neurodegeneration. Visual neuroscience 2005;22:637-648. [PubMed: 16332275]

18. Anderson MG, Smith RS, Hawes NL, et al. Mutations in genes encoding melanosomal proteins cause pigmentary glaucoma in DBA/2J mice. Nature genetics 2002;30:81-85. [PubMed: 11743578] 
19. Jakobs TC, Libby RT, Ben Y, John SW, Masland RH. Retinal ganglion cell degeneration is topological but not cell type specific in DBA/2J mice. The Journal of cell biology 2005;171:313-325. [PubMed: 16247030]

20. Bayer AU, Neuhardt T, May AC, et al. Retinal morphology and ERG response in the DBA/2NNia mouse model of angle-closure glaucoma. Investigative ophthalmology \& visual science 2001;42:1258-1265. [PubMed: 11328737]

21. Nagaraju M, Saleh M, Porciatti V. IOP-dependent retinal ganglion cell dysfunction in glaucomatous DBA/2J mice. Invest Ophthalmol Vis Sci 2007;48:4573-4579. [PubMed: 17898280]

22. Li Y, Semaan SJ, Schlamp CL, Nickells RW. Dominant inheritance of retinal ganglion cell resistance to optic nerve crush in mice. BMC neuroscience 2007;8:19. [PubMed: 17338819]

23. Libby RT, Li Y, Savinova OV, et al. Susceptibility to neurodegeneration in a glaucoma is modified by Bax gene dosage. PLoS genetics 2005;1:17-26. [PubMed: 16103918]

24. Ahmed F, Brown KM, Stephan DA, Morrison JC, Johnson EC, Tomarev SI. Microarray analysis of changes in mRNA levels in the rat retina after experimental elevation of intraocular pressure. Investigative ophthalmology \& visual science 2004;45:1247-1258. [PubMed: 15037594]

25. Stasi K, Nagel D, Yang X, et al. Complement component 1Q (C1Q) upregulation in retina of murine, primate, and human glaucomatous eyes. Investigative ophthalmology \& visual science 2006;47:1024-1029. [PubMed: 16505037]

26. Steele MR, Inman DM, Calkins DJ, Horner PJ, Vetter ML. Microarray analysis of retinal gene expression in the DBA/2J model of glaucoma. Investigative ophthalmology \& visual science 2006;47:977-985. [PubMed: 16505032]

27. Stevens B, Allen NJ, Vazquez LE, et al. The classical complement cascade mediates CNS synapse elimination. Cell 2007;131:1164-1178. [PubMed: 18083105]

28. Anderson MG, Libby RT, Gould DB, Smith RS, John SW. High-dose radiation with bone marrow transfer prevents neurodegeneration in an inherited glaucoma. Proceedings of the National Academy of Sciences of the United States of America 2005;102:4566-4571. [PubMed: 15758074]

29. Bosco A, Inman DM, Steele MR, et al. Reduced retina microglial activation and improved optic nerve integrity with minocycline treatment in the DBA/2J mouse model of glaucoma. Invest Ophthalmol Vis Sci 2008;49:1437-1446. [PubMed: 18385061]

30. Zhou X, Li F, Ge J, et al. Retinal ganglion cell protection by 17-beta-estradiol in a mouse model of inherited glaucoma. Developmental neurobiology 2007;67:603-616. [PubMed: 17443811]

31. Zhong L, Bradley J, Schubert W, et al. Erythropoietin promotes survival of retinal ganglion cells in DBA/2J glaucoma mice. Invest Ophthalmol Vis Sci 2007;48:1212-1218. [PubMed: 17325165]

32. Ward MS, Khoobehi A, Lavik EB, Langer R, Young MJ. Neuroprotection of retinal ganglion cells in DBA/2J mice with GDNF-loaded biodegradable microspheres. Journal of pharmaceutical sciences 2007;96:558-568. [PubMed: 17177208]

33. Zhou Y, Grinchuk O, Tomarev SI. Transgenic mice expressing the Tyr437His mutant of human myocilin protein develop glaucoma. Investigative ophthalmology \& visual science 2008;49:19321939. [PubMed: 18436825]

34. Alward WL, Fingert JH, Coote MA, et al. Clinical features associated with mutations in the chromosome 1 open-angle glaucoma gene (GLC1A). The New England journal of medicine 1998;338:1022-1027. [PubMed: 9535666]

35. Malyukova I, Lee HS, Fariss RN, Tomarev SI. Mutated mouse and human myocilins have similar properties and do not block general secretory pathway. Investigative ophthalmology \& visual science 2006;47:206-212. [PubMed: 16384964]

36. Fingert JH, Stone EM, Sheffield VC, Alward WL. Myocilin glaucoma. Survey of ophthalmology 2002;47:547-561. [PubMed: 12504739]

37. Gould DB, Reedy M, Wilson LA, Smith RS, Johnson RL, John SW. Mutant myocilin nonsecretion in vivo is not sufficient to cause glaucoma. Molecular and cellular biology 2006;26:8427-8436. [PubMed: 16954374]

38. Mabuchi F, Lindsey JD, Aihara M, Mackey MR, Weinreb RN. Optic nerve damage in mice with a targeted type I collagen mutation. Investigative ophthalmology \& visual science 2004;45:1841-1845. [PubMed: 15161848] 
39. Ittner LM, Schwerdtfeger K, Kunz TH, et al. Transgenic mice with ocular overexpression of an adrenomedullin receptor reflect human acute angle-closure glaucoma. Clin Sci (Lond) 2008;114:4958. [PubMed: 17608625]

40. Harada T, Harada C, Nakamura K, et al. The potential role of glutamate transporters in the pathogenesis of normal tension glaucoma. The Journal of clinical investigation 2007;117:1763-1770. [PubMed: 17607354]

41. Takeshi, I.; Zai-Long, C.; Fumie, Y., et al. Three potential mouse model for glaucoma. International Congress for Eye Research; Beijing, China. 2008. [ICER abstract GL1]

42. Gould DB, Smith RS, John SW. Anterior segment development relevant to glaucoma. The International journal of developmental biology 2004;48:1015-1029. [PubMed: 15558492]

43. Sowden JC. Molecular and developmental mechanisms of anterior segment dysgenesis. Eye (London, England) 2007;21:1310-1318.

44. Cvekl A, Tamm ER. Anterior eye development and ocular mesenchyme: new insights from mouse models and human diseases. Bioessays 2004;26:374-386. [PubMed: 15057935]

45. Smith RS, Zabaleta A, Kume T, et al. Haploinsufficiency of the transcription factors FOXC1 and FOXC2 results in aberrant ocular development. Human molecular genetics 2000;9:1021-1032. [PubMed: 10767326]

46. Libby RT, Smith RS, Savinova OV, et al. Modification of ocular defects in mouse developmental glaucoma models by tyrosinase. Science (New York, NY 2003;299:1578-1581.

47. Sasaki T, Watanabe W, Muranishi Y, et al. Elevated intraocular pressure, optic nerve atrophy, and impaired retinal development in ODAG transgenic mice. Investigative ophthalmology \& visual science 2009;50:242-248. [PubMed: 18791169]

48. De Marco N, Buono M, Troise F, Diez-Roux G. Optineurin increases cell survival and translocates to the nucleus in a Rab8-dependent manner upon an apoptotic stimulus. The Journal of biological chemistry 2006;281:16147-16156. [PubMed: 16569640]

49. Wang WH, McNatt LG, Pang IH, et al. Increased expression of the WNT antagonist sFRP-1 in glaucoma elevates intraocular pressure. The Journal of clinical investigation 2008;118:1056-1064. [PubMed: 18274669]

50. Gaasterland D, Kupfer C. Experimental glaucoma in the rhesus monkey. Invest Ophthalmol 1974;13:455-457. [PubMed: 4208801]

51. WoldeMussie E, Feldman B. Effect of chronically elevated intraocular pressure on loss of retinal ganglion cells in rats. [ARVO Abstract] Invest Ophthalmol Vis Sci 1997;38:S159. Abstract 787.

52. Wijono M, WoldeMussie E, Ruiz G. Process of retinal ganglion damage by elevated intraocular pressure in rat eyes. [ARVO Abstract] Invest Ophthalmol Vis Sci 1999;40:S672. Abstract 3545.

53. Gross RL, Ji J, Chang P, et al. A mouse model of elevated intraocular pressure: retina and optic nerve findings. Trans Am Ophthalmol Soc 2003;101:163-169. discussion 169-171. [PubMed: 14971574]

54. Ueda J, Sawaguchi S, Hanyu T, et al. Experimental glaucoma model in the rat induced by laser trabecular photocoagulation after an intracameral injection of India ink. Japanese journal of ophthalmology 1998;42:337-344. [PubMed: 9822959]

55. Levkovitch-Verbin H, Quigley HA, Martin KR, Valenta D, Baumrind LA, Pease ME. Translimbal laser photocoagulation to the trabecular meshwork as a model of glaucoma in rats. Invest Ophthalmol Vis Sci 2002;43:402-410. [PubMed: 11818384]

56. Grozdanic SD, Betts DM, Sakaguchi DS, Allbaugh RA, Kwon YH, Kardon RH. Laser-induced mouse model of chronic ocular hypertension. Invest Ophthalmol Vis Sci 2003;44:4337-4346. [PubMed: 14507878]

57. Ji J, Chang P, Pennesi ME, et al. Effects of elevated intraocular pressure on mouse retinal ganglion cells. Vision Res 2005;45:169-179. [PubMed: 15581918]

58. Aihara M, Lindsey JD, Weinreb RN. Experimental mouse ocular hypertension: establishment of the model. Invest Ophthalmol Vis Sci 2003;44:4314-4320. [PubMed: 14507875]

59. Morrison JC, Moore CG, Deppmeier LM, Gold BG, Meshul CK, Johnson EC. A rat model of chronic pressure-induced optic nerve damage. Exp Eye Res 1997;64:85-96. [PubMed: 9093024]

60. Fortune B, Bui BV, Morrison JC, et al. Selective ganglion cell functional loss in rats with experimental glaucoma. Invest Ophthalmol Vis Sci 2004;45:1854-1862. [PubMed: 15161850] 
61. Johnson EC, Cepurna WO, Jia L, Morrison JC. The use of cyclodialysis to limit exposure to elevated intraocular pressure in rat glaucoma models. Exp Eye Res 2006;83:51-60. [PubMed: 16530758]

62. Johnson EC, Jia L, Cepurna WO, Doser TA, Morrison JC. Global changes in optic nerve head gene expression after exposure to elevated intraocular pressure in a rat glaucoma model. Investigative ophthalmology \& visual science 2007;48:3161-3177. [PubMed: 17591886]

63. Shareef SR, Garcia-Valenzuela E, Salierno A, Walsh J, Sharma SC. Chronic ocular hypertension following episcleral venous occlusion in rats. Exp Eye Res 1995;61:379-382. [PubMed: 7556500]

64. Laquis S, Chaudhary P, Sharma SC. The patterns of retinal ganglion cell death in hypertensive eyes. Brain Res 1998;784:100-104. [PubMed: 9518569]

65. Garcia-Valenzuela E, Shareef S, Walsh J, Sharma SC. Programmed cell death of retinal ganglion cells during experimental glaucoma. Exp Eye Res 1995;61:33-44. [PubMed: 7556468]

66. Ruiz-Ederra J, Verkman AS. Mouse model of sustained elevation in intraocular pressure produced by episcleral vein occlusion. Exp Eye Res 2006;82:879-884. [PubMed: 16310189]

67. Morrison JC, Johnson EC, Cepurna W, Jia L. Understanding mechanisms of pressure-induced optic nerve damage. Prog Retin Eye Res 2005;24:217-240. [PubMed: 15610974]

68. Goldblum D, Mittag T. Prospects for relevant glaucoma models with retinal ganglion cell damage in the rodent eye. Vision Res 2002;42:471-478. [PubMed: 11853763]

69. Moreno MC, Marcos HJ, Oscar Croxatto J, et al. A new experimental model of glaucoma in rats through intracameral injections of hyaluronic acid. Exp Eye Res 2005;81:71-80. [PubMed: 15978257]

70. Urcola JH, Hernandez M, Vecino E. Three experimental glaucoma models in rats: comparison of the effects of intraocular pressure elevation on retinal ganglion cell size and death. Exp Eye Res 2006;83:429-437. [PubMed: 16682027]

71. Mermoud A, Baerveldt G, Mickler DS, Wu GS, Rao NA. Animal model for uveitic glaucoma. Graefes Arch Clin Exp Ophthalmol 1994;232:553-560. [PubMed: 7959095]

72. Levkovitch-Verbin H, Harris-Cerruti C, Groner Y, Wheeler LA, Schwartz M, Yoles E. RGC death in mice after optic nerve crush injury: oxidative stress and neuroprotection. Invest Ophthalmol Vis Sci 2000;41:4169-4174. [PubMed: 11095611]

73. Berkelaar M, Clarke DB, Wang YC, Bray GM, Aguayo AJ. Axotomy results in delayed death and apoptosis of retinal ganglion cells in adult rats. J Neurosci 1994;14:4368-4374. [PubMed: 8027784]

74. Blair M, Pease ME, Hammond J, et al. Effect of glatiramer acetate on primary and secondary degeneration of retinal ganglion cells in the rat. Investigative ophthalmology \& visual science 2005;46:884-890. [PubMed: 15728544]

75. Schwartz M. Optic nerve crush: protection and regeneration. Brain research bulletin 2004;62:467471. [PubMed: 15036559]

76. Fisher J, Levkovitch-Verbin H, Schori H, et al. Vaccination for neuroprotection in the mouse optic nerve: implications for optic neuropathies. J Neurosci 2001;21:136-142. [PubMed: 11150329]

77. Beirowski B, Babetto E, Coleman MP, Martin KR. The WldS gene delays axonal but not somatic degeneration in a rat glaucoma model. Eur J Neurosci 2008;28:1166-1179. [PubMed: 18783366]

78. Whitmore AV, Libby RT, John SW. Glaucoma: thinking in new ways-a role for autonomous axonal self-destruction and other compartmentalised processes? Prog Retin Eye Res 2005;24:639-662. [PubMed: 15953750]

79. Vrabec JP, Levin LA. The neurobiology of cell death in glaucoma. Eye 2007;21(Suppl 1):S11-14. [PubMed: 18157171]

80. Sun Q, Ooi VE, Chan SO. N-methyl-D-aspartate-induced excitotoxicity in adult rat retina is antagonized by single systemic injection of MK-801. Exp Brain Res 2001;138:37-45. [PubMed: 11374081]

81. Yang XL. Characterization of receptors for glutamate and GABA in retinal neurons. Progress in neurobiology 2004;73:127-150. [PubMed: 15201037]

82. Li Y, Schlamp CL, Poulsen GL, Jackson MW, Griep AE, Nickells RW. p53 regulates apoptotic retinal ganglion cell death induced by N-methyl-D-aspartate. Mol Vis 2002;8:341-350. [PubMed: 12355059] 
83. Vorwerk CK, Lipton SA, Zurakowski D, Hyman BT, Sabel BA, Dreyer EB. Chronic low-dose glutamate is toxic to retinal ganglion cells. Toxicity blocked by memantine. Invest Ophthalmol Vis Sci 1996;37:1618-1624. [PubMed: 8675405]

84. Dreyer EB, Zurakowski D, Schumer RA, Podos SM, Lipton SA. Elevated glutamate levels in the vitreous body of humans and monkeys with glaucoma. Arch Ophthalmol 1996;114:299-305. [PubMed: 8600890]

85. Honkanen RA, Baruah S, Zimmerman MB, et al. Vitreous amino acid concentrations in patients with glaucoma undergoing vitrectomy. Arch Ophthalmol 2003;121:183-188. [PubMed: 12583783]

86. Wamsley S, Gabelt BT, Dahl DB, et al. Vitreous glutamate concentration and axon loss in monkeys with experimental glaucoma. Arch Ophthalmol 2005;123:64-70. [PubMed: 15642814]

87. Levkovitch-Verbin H, Martin KR, Quigley HA, Baumrind LA, Pease ME, Valenta D. Measurement of amino acid levels in the vitreous humor of rats after chronic intraocular pressure elevation or optic nerve transection. J Glaucoma 2002;11:396-405. [PubMed: 12362078]

88. Chaudhary P, Ahmed F, Sharma SC. MK801-a neuroprotectant in rat hypertensive eyes. Brain Res 1998;792:154-158. [PubMed: 9593871]

89. Yoles E, Muller S, Schwartz M. NMDA-receptor antagonist protects neurons from secondary degeneration after partial optic nerve crush. J Neurotrauma 1997;14:665-675. [PubMed: 9337128]

90. Ju WK, Kim KY, Angert M, et al. Memantine blocks mitochondrial OPA1 and cytochrome c release, and subsequent apoptotic cell death in glaucomatous retina. Investigative ophthalmology \& visual science. 2008

91. Buchi ER. Cell death in rat retina after pressure-induced ischaemia-reperfusion insult: electron microscopic study. II. Outer nuclear layer. Japanese journal of ophthalmology 1992;36:62-68. [PubMed: 1635297]

92. Buchi ER. Cell death in the rat retina after a pressure-induced ischaemia-reperfusion insult: an electron microscopic study. I. Ganglion cell layer and inner nuclear layer. Exp Eye Res 1992;55:605-613. [PubMed: 1483506]

93. Buchi ER, Suivaizdis I, Fu J. Pressure-induced retinal ischemia in rats: an experimental model for quantitative study. Ophthalmologica 1991;203:138-147. [PubMed: 1775302]

94. Szabo ME, Droy-Lefaix MT, Doly M, Carre C, Braquet P. Ischemia and reperfusion-induced histologic changes in the rat retina. Demonstration of a free radical-mediated mechanism. Invest Ophthalmol Vis Sci 1991;32:1471-1478. [PubMed: 2016129]

95. Stefansson E, Wilson CA, Schoen T, Kuwabara T. Experimental ischemia induces cell mitosis in the adult rat retina. Invest Ophthalmol Vis Sci 1988;29:1050-1055. [PubMed: 3417399]

96. Mosinger JL, Olney JW. Photothrombosis-induced ischemic neuronal degeneration in the rat retina. Exp Neurol 1989;105:110-113. [PubMed: 2744125]

97. Chauhan BC, LeVatte TL, Jollimore CA, et al. Model of endothelin-1-induced chronic optic neuropathy in rat. Invest Ophthalmol Vis Sci 2004;45:144-152. [PubMed: 14691166]

98. Chauhan BC, Levatte TL, Garnier KL, et al. Semiquantitative optic nerve grading scheme for determining axonal loss in experimental optic neuropathy. Invest Ophthalmol Vis Sci 2006;47:634640. [PubMed: 16431961]

99. Taniguchi T, Okada K, Haque MS, Sugiyama K, Kitazawa Y. Effects of endothelin-1 on intraocular pressure and aqueous humor dynamics in the rabbit eye. Curr Eye Res 1994;13:461-464. [PubMed: 7523028]

100. Otori, Y. Use of purified retinal ganglion cells for an in vitro model to study glaucoma. In: TombranTink, J.; Barnstable, CJ.; Shields, MB., editors. Ophthalmology Research: Mechanisms of the Glaucomas. Totowa, NJ: Humana Press; 2008. p. 601-607.

101. Meyer-Franke A, Kaplan MR, Pfrieger FW, Barres BA. Characterization of the signaling interactions that promote the survival and growth of developing retinal ganglion cells in culture. Neuron 1995;15:805-819. [PubMed: 7576630]

102. Barres BA, Silverstein BE, Corey DP, Chun LL. Immunological, morphological, and electrophysiological variation among retinal ganglion cells purified by panning. Neuron 1988;1:791-803. [PubMed: 2908449]

103. Krishnamoorthy RR, Agarwal P, Prasanna G, et al. Characterization of a transformed rat retinal ganglion cell line. Brain Res Mol Brain Res 2001;86:1-12. [PubMed: 11165366] 
104. Agarwal N, Agarwal R, Kumar DM, et al. Comparison of expression profile of neurotrophins and their receptors in primary and transformed rat retinal ganglion cells. Mol Vis 2007;13:1311-1318. [PubMed: 17679933]

105. Frassetto LJ, Schlieve CR, Lieven CJ, et al. Kinase-dependent differentiation of a retinal ganglion cell precursor. Invest Ophthalmol Vis Sci 2006;47:427-438. [PubMed: 16384993]

106. Zhang SS, Fu XY, Barnstable CJ. Tissue culture studies of retinal development. Methods 2002;28:439-447. [PubMed: 12507462]

107. Seigel GM. The golden age of retinal cell culture. Mol Vis 1999;5:4. [PubMed: 10209197]

108. Johnson TV, Martin KR. Development and characterization of an adult retinal explant organotypic tissue culture system as an in vitro intraocular stem cell transplantation model. Invest Ophthalmol Vis Sci 2008;49:3503-3512. [PubMed: 18408186] 


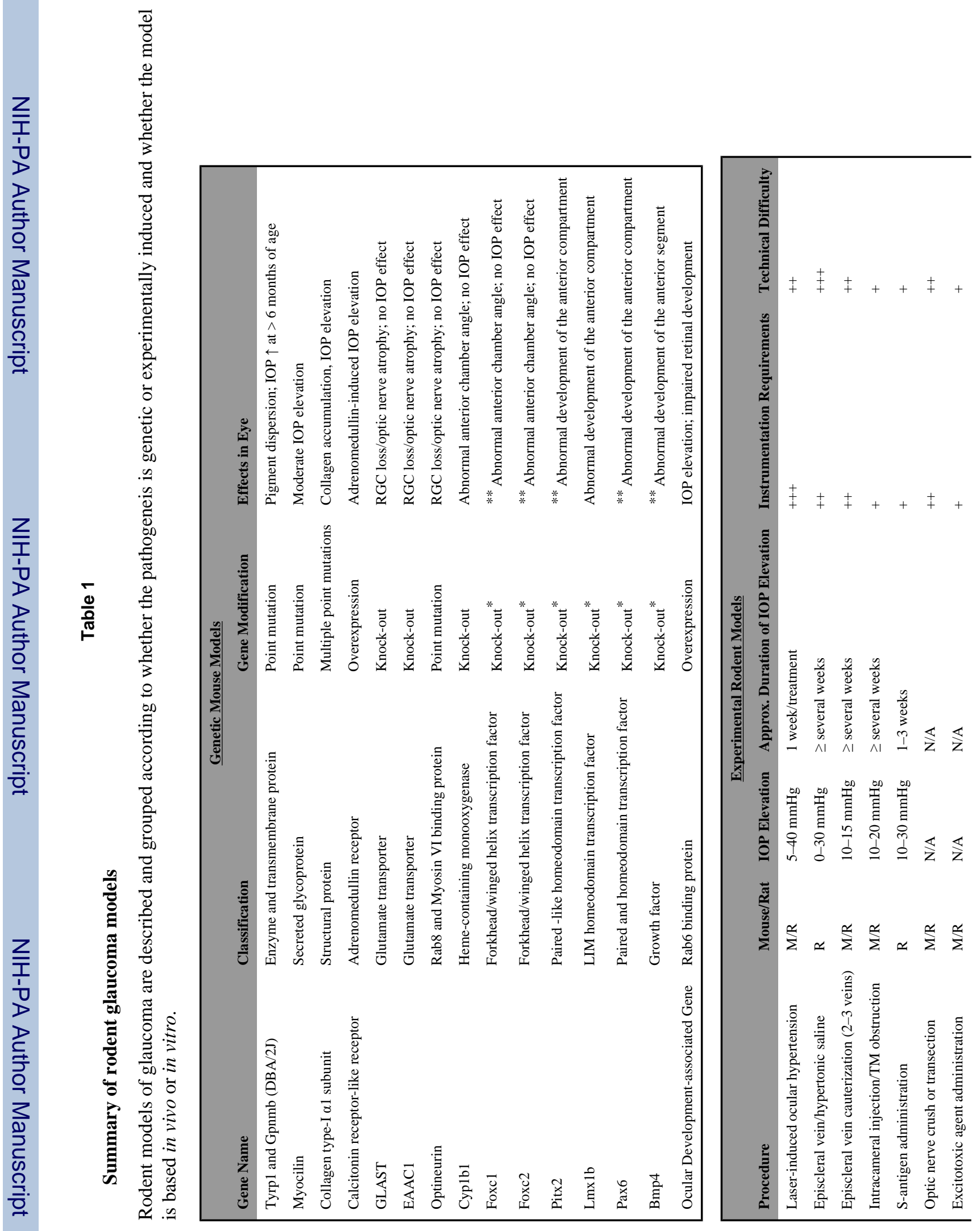

Brain Res Bull. Author manuscript; available in PMC 2011 February 15. 


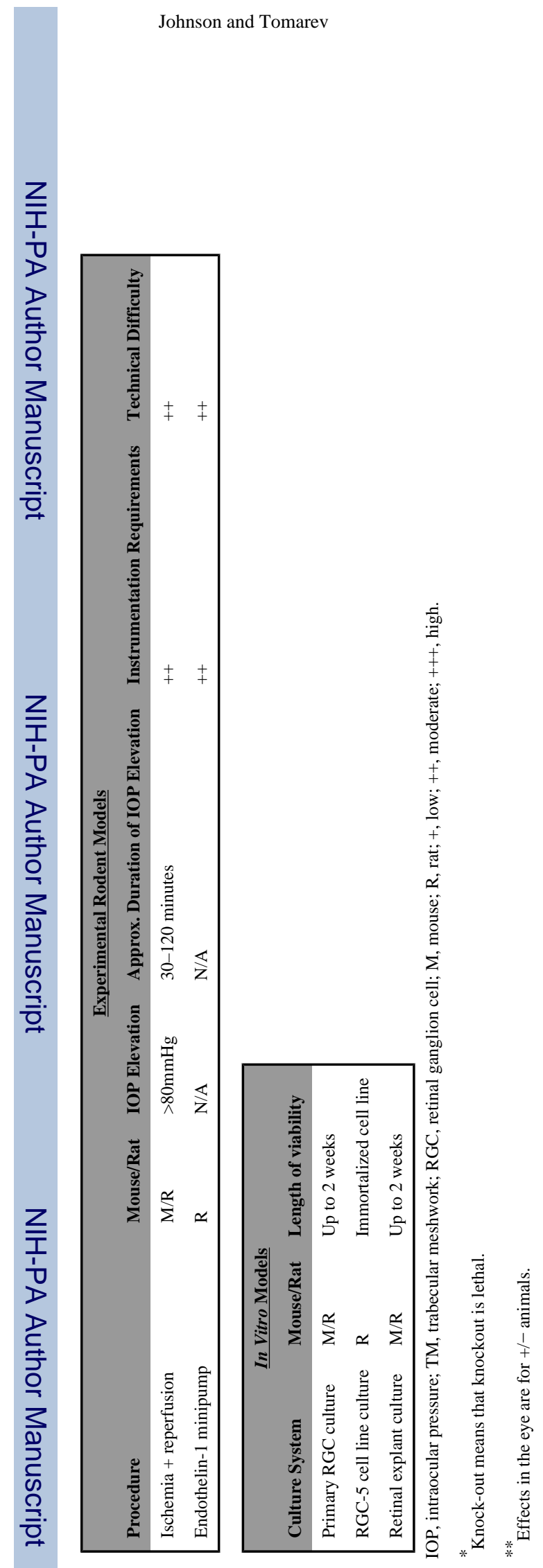

Brain Res Bull. Author manuscript; available in PMC 2011 February 15. 